\author{
ARTIGO \\ CO https://doi.org/10.22481/praxisedu.v16i38.6012
}

\title{
A BNCC NA CONTRAMÃO DAS DEMANDAS SOCIAIS: PLANEJAMENTO COM E PLANEJAMENTO PARA
}

BNCC IN CONTRACTING SOCIAL DEMANDS: PLANNING WITH AND PLANNING FOR

\author{
BNCC EN CONTRATACIÓN DE DEMANDAS SOCIALES: PLANIFICANDO CON Y \\ PLANIFICANDO PARA
}

Rafael Marques Gonçalves Universidade Federal do Acre- Brasil

Tânia Mara Rezende Machado Universidade Federal do Acre- Brasil

Maria José Nascimento Correia Universidade Federal do Acre- Brasil

\begin{abstract}
Resumo: Este trabalho discute a implementação da Base Nacional Comum Curricular (BNCC) e seu desalinhamento com as demandas sociais, e apresenta dois possíveis currículos: aquele que deslinda um "planejamento para", ou seja, que de maneira verticalizada prescreve o trabalho pedagógico para a escola, e o currículo que dialoga com o real que the escapa, dando margem para o "planejamento com". A discussão aqui proposta apresenta também um claro posicionamento: o de afirmar a necessidade de uma organização de conteúdos base para a educação nacional, mas que não se una aos instrumentos reguladores do trabalho pedagógico, sabendo-se que isto não é possível sem que se encare o aspecto político social da qual ela faz parte. Neste sentido, por meio de uma abordagem qualitativa, visitamos o que tem se discutido sobre a BNCC e a situamos no contexto das políticas neoliberais, que mais enfaticamente nos últimos anos tem posto as políticas educacionais demandadas pela sociedade em desvantagem. Dessa maneira, tomamos como essenciais os trabalhos de Cury (2018), Branco [et al.] (2018), Gonçalves (2018), Sacristán (2017), Sussekind (2014), Freire (1986), entre outros, que, mesmo com perspectivas diferentes, são de grande contribuição para o debate no campo do currículo, e analisamos dados disponibilizados pelo ministério da educação via internet, em seu site oficial. Ao dialogar com o referencial mencionado, percebemos a BNCC existente como uma forma de currículo prescrito e vislumbramos uma base que possibilite uma construção coletiva e permanente.
\end{abstract}

Palavras-chave: BNCC; Currículo; sociedade.

Abstract: Abstract: This paper discusses the implementation of the Common National Curriculum Base (BNCC) and its misalignment with social demands, and presents two possible curricula: one that 
dislocates a "planning for", that is, that vertically prescribes the pedagogical work for the school, and the curriculum that dialogues with the real that escapes it, allowing for "planning with". The discussion proposed here also presents a clear position: to affirm the need for a basic content organization for national education, but not to join the regulatory instruments of pedagogical work, knowing that this is not possible without facing the social political aspect of which she is part. In this sense, through a qualitative approach, we visit what has been discussed about the BNCC and place it in the context of neoliberal policies, which more emphatically in recent years has put the educational policies demanded by society at a disadvantage. Thus, we take as essential the works of Cury (2018), Branco [et al.] (2018), Gonçalves (2018), Sacristán (2017), Sussekind (2014), Freire (1986), among others, that even from different perspectives, are of great contribution to the debate in the curriculum field, and we analyze data made available by the ministry of education via the internet on its official website. In dialoguing with the referenced framework, we perceive the existing BNCC as a prescribed form of curriculum and glimpse a basis that enables a collective and permanent construction.

Keywords: BNCC; Curriculum; society.

Resumen: Este documento discute la implementación de la Base Curricular Nacional Común (BNCC) y su desalineación con las demandas sociales, y presenta dos posibles planes de estudio: uno que disloca una "planificación para", es decir, que prescribe verticalmente el trabajo pedagógico para la escuela y el plan de estudios que dialoga con lo real que se le escapa, lo que permite "planificar con". La discusión propuesta aquí también presenta una posición clara: afirmar la necesidad de una organización de contenido básico para la educación nacional, pero no unirse a los instrumentos reguladores del trabajo pedagógico, sabiendo que esto no es posible sin enfrentar El aspecto político social del cual ella es parte. En este sentido, a través de un enfoque cualitativo, visitamos lo que se ha discutido sobre el BNCC y lo ubicamos en el contexto de las políticas neoliberales, lo que más enfáticamente en los últimos años ha puesto en desventaja las políticas educativas exigidas por la sociedad. Así, tomamos como esenciales los trabajos de Cury (2018), Branco [et al.] (2018), Gonçalves (2018), Sacristán (2017), Sussekind (2014), Freire (1986), entre otros, que incluso desde diferentes perspectivas, son de gran contribución al debate en el campo del plan de estudios, y analizamos los datos proporcionados por el ministerio de educación a través de internet en su sitio web oficial. Al dialogar con el marco referenciado, percibimos el BNCC existente como una forma prescrita de currículo y vislumbramos una base que permite una construcción colectiva y permanente.

Palabras clave: BNCC; Plan de estudios; sociedad

\section{Introdução}

O que inspirou a escrita deste trabalho foram as discussões realizadas no decurso da disciplina Tópicos Especiais em Educação, da grade curricular do curso Mestrado em Educação do Programa de Pós-Graduação em Educação da Universidade Federal do Acre UFAC. Temos como principal objetivo analisar os processos que envolveram a construção e implementação da Base Nacional Comum Curricular e seu desalinhamento com as demandas sociais. Para tanto, compreendemo-la como currículo, mesmo não sendo esta a definição 
adotada pela oficialidade, ou seja, pelo governo. Essa compreensão está ligada às definições de currículo, que não se fecha apenas no prescrito, mas está fortemente ligada às demandas diárias dos saberes construídos, da relação professor-aluno e, com ela, os rearranjos do subsídio teórico apresentado.

Adotamos um referencial diverso em abordagens, e conscientes de suas implicações, justificamos por duas centrais razões. Em primeiro lugar, porque a disciplina acima referida nos possibilitou o encontro com as diferentes concepções e através dele não apenas observamos suas diferenças, como também suas convergências, o que não configura neutralidade epistemológica, mas racionalidade científica. Em segundo lugar, sabemos que o que permite a convivência das diferentes percepções no campo da pesquisa em educação é, fundamentalmente, a consciência de que uma abordagem não se sobrepõe à outra, uma vez que, além de apresentarem suas contribuições, estão situadas historicamente, permitindo-nos inferir que cada uma possui também limitações e precisam ser constantemente revistas, podendo, assim, complementarem-se.

Dessa feita, nos utilizamos de autores de perspectiva crítica e pós-crítica do currículo, com a intenção de aproximar os saberes através delas produzidos, analisando a BNCC à luz das definições de currículo apresentadas por Cury (2018), Gonçalves (2018), Sacristán (2017) e Sussekind (2014), além de análises sobre política, sociedade e educação com Branco [et al.] (2018), Goodson (1997), Freire (1986), entre outros.

A parte empírica da pesquisa foi realizada principalmente por meio das informações disponíveis no site oficial do Ministério da educação (basenacionalcomum.mec.gov.br/), de onde destacamos os marcos da elaboração e os processos de implementação da Base, que nos possibilitou discutir, no primeiro item do texto, o contexto político de elaboração da BNCC e suas implicações nos processos de decisão muitas vezes unilaterais. Tal contexto deu conta de seguir a análise do que chamamos planejamento para, onde se evidencia o papel das políticas neoliberais no currículo desalinhando-o com as demandas sociais.

A segunda parte do texto revela nossa identificação com políticas educacionais democráticas, onde vislumbramos uma Base Nacional Comum necessária, ao analisarmos as limitações de um currículo nacional e algumas reivindicações cotidianas de professores. Esperamos que este trabalho seja uma contribuição significativa ao debate tanto recente quanto necessário que se tem delineado nos últimos anos, acompanhando um processo de mudanças nas políticas educacionais, parte de um contexto mais geral de reformas. 


\section{A BNCC no contexto de desestruturação política}

Todos os processos que envolveram elaboração e implementação da Base Nacional Comum Curricular são indissociáveis do contexto político vivido pelo Brasil principalmente nos últimos anos. Nunca é demasiado lembrar que a aprovação da BNCC ocorreu em um conturbado momento político em que se deu início uma exasperada disputa de poder, culminando no afastamento da presidenta eleita Dilma Rousseff e no empoderamento do ilegítimo, na fala de CURY (2018, p. 66), “(ocupante do cargo de) Presidente da República em 2017", Michel Temer.

O debate sobre a necessidade de implementação de um currículo básico comum surge com a Constituição Federal de 1988, não explicitando uma base de conhecimentos nacionais, mas assegurando o "respeito aos valores culturais e artísticos, nacionais e regionais" (CF, 1988, art. 210). Tal debate intensifica-se a partir da Lei de Diretrizes e Bases da Educação Nacional de 1996, que assegura para a Educação Básica que

Os currículos do ensino fundamental e médio devem ter uma base nacional comum, a ser complementada, em cada sistema de ensino e estabelecimento escolar, por uma parte diversificada, exigida pelas características regionais e locais da sociedade, da cultura, da economia e da clientela. (LDBEN, 1996, art. 26).

De 1997, com a elaboração dos PCNs, até 2014, com a 2a Conferência Nacional pela Educação (Conae), temos um longo processo de organização da educação nacional, que inclui o Programa Currículo em Movimento (2008 a 2010), as Diretrizes Curriculares Nacionais Gerais para a Educação Básica (DCNs), Pacto Nacional pela Alfabetização na Idade Certa (PNAIC, 2012), Pacto Nacional de Fortalecimento do Ensino Médio (PNFEM, 2013), a regulamentação do Plano Nacional de Educação (PNE, 2014). Por faltar fôlego, destacaremos nesta primeira seção apenas as fases finais de mobilização para o debate em torno da BNCC, de 2014 a 2018, enfatizando a mudança de governo e a aceleração nos processos decisórios, tendo como consequência a drástica redução da participação popular, enfatizada nesta discussão.

Constituiu importante marco para as mobilizações em torno da BNCC a $2^{\mathrm{a}}$ Conae, ocorrida entre 19 e 23 de novembro de 2014, da qual participaram através de representantes mais de 40 entidades, em diferentes níveis e categorias, tais como a União Nacional dos Estudantes (UNE), a Comissão Nacional de Educação Escolar Indígena (CNEEI), 
Movimentos Sociais Afro-Brasileiros, Centrais Sindicais dos Trabalhadores (CUT e UGT) e Associação Nacional de Pós-graduação e Pesquisa em Educação (ANPED). É sempre imperioso considerar que, situando a educação num espaço de disputas, há sempre diferenças nas formas de participação de cada representação, tendo em vista o seu poder de fala, a sua representatividade, ou seu (des)alinhamento com as macro políticas, mas, ainda assim, é valido destacar como positiva a participação dos grupos que foram chamados para o debate.

A primeira versão da BNCC é disponibilizada em 16 de setembro de 2015, quase um ano depois da $2^{\text {a }}$ Conae, e nesse percurso podemos destacar o I Seminário Interinstitucional para elaboração da BNCC, realizado entre 17 e 19 de junho, que reuniu a comissão de especialistas nomeados pela Portaria n. 592, de 17 de junho de 2015. Em maio de 2016, após somente 14 dias de mobilização das escolas para o debate (2 a 15 de dezembro de 2015), a BNCC é disponibilizada em sua $2^{\mathrm{a}}$ versão, a qual é discutida por professores, gestores e especialistas em 27 Seminários Estaduais, de 23 de junho a 10 de agosto de 2016, mês em que a presidenta Dilma Rousseff foi destituída da liderança do executivo.

A terceira versão da base começa a ser redigida no mesmo mês (agosto), já na liderança do interino Michel Temer, em um processo "colaborativo" (MEC, 2016), em que em que foram considerados pareceres de diversos profissionais, cujo processo de escolha não fica claro. A versão final da BNCC foi entregue ao Conselho Nacional de Educação (CNE) em abril de 2017 e homologada em dezembro do mesmo ano.

Todo esse histórico, que está disponível com mais detalhes no site do Ministério da Educação, segue resumido em tabela, para analisarmos com mais especificidade.

Tabela 01: Percurso da implementação da BNCC (2014-1018)

\begin{tabular}{|c|c|c|}
\hline Data & Atividade & $\begin{array}{l}\text { Presidente(a) } \\
\text { em exercício }\end{array}$ \\
\hline $25 / 06 / 14$ & $\begin{array}{l}\text { Lei n. } 13.005 \text { - regulamenta o Plano Nacional de Educação } \\
\text { (PNE). }\end{array}$ & \multirow{7}{*}{ Dilma Rousseff } \\
\hline $19-23 / 11 / 14$ & 2ª Conferência Nacional pela Educação (Conae). & \\
\hline $17-19 / 06 / 15$ & I Seminário Interinstitucional para elaboração da BNC. & \\
\hline $16 / 09 / 15$ & 1a versão da BNCC é disponibilizada. & \\
\hline $02-15 / 12 / 15$ & $\begin{array}{l}\text { Mobilização das escolas para discussão do documento } \\
\text { preliminar da base. }\end{array}$ & \\
\hline $03 / 05 / 16$ & $2^{\underline{a}}$ versão da BNCC é disponibilizada. & \\
\hline $\begin{array}{l}23 / 06 \\
10 / 08 / 16\end{array}$ & $\begin{array}{l}\text { Seminários Estaduais com professores, gestores e } \\
\text { especialistas para debater a segunda versão da BNCC. }\end{array}$ & \\
\hline $08 / 16$ & Redação da $3^{\underline{a}}$ versão da BNCC. & \multirow[b]{3}{*}{ Michel Temer } \\
\hline $12 / 16$ & Pareceres de especialistas. & \\
\hline $04 / 17$ & Entrega da versão final da BNCC. & \\
\hline
\end{tabular}




\begin{tabular}{|c|c|}
\hline $20 / 12 / 17$ & Homologação da BNCC. \\
\hline $02 / 04 / 18$ & Entrega da $3^{\mathrm{a}}$ versão da BNCC do Ensino Médio. \\
\hline $05 / 04 / 18$ & $\begin{array}{l}\text { Programa de Apoio à Implementação da Base Nacional } \\
\text { Comum Curricular ProBNCC. }\end{array}$ \\
\hline 02/08/18 & Mobilização das escolas para o debate. \\
\hline $14 / 12 / 18$ & Homologação da BNCC do Ensino Médio. \\
\hline
\end{tabular}

Fonte: os autores, a partir de dados disponibilizados no site do Ministério da Educação (http://basenacionalcomum.mec.gov.br).

Analisando a tabela, podemos notar que entre junho de 2014 e agosto de 2016, houve lugar para um aflorado debate com espaço para participação de muitos setores da sociedade, especialmente através da $2^{\text {a }}$ Conae e mesmo apontada a necessidade de uma Base Comum Nacional em quatro das metas do PNE, não havia sido aprovada até então, assegurando maior participação possível na elaboração de tal documento. Após a destituição da presidenta Dilma, no entanto, aceleram-se os processos decisórios, reduzem-se os espaços de comunicação, garantindo-se sua homologação na versão final em pouco mais de um ano, com insignificante número de debates, e segue-se na mesma lógica a aceleração para implementação da BNCC do Ensino Médio.

Merecem destaque os pareceres de especialistas em dezembro de 2016, entre a redação da $3^{a}$ versão da base e a entrega de sua versão final. Duas questões a serem consideradas é quem são os tais especialistas e quais critérios são utilizados para selecioná-los. A portaria $\mathrm{n}^{\circ}$ 592, de 17 e junho de 2015, instituía que a comissão de especialistas para a elaboração da proposta da BNCC seria

[...] composta por 116 membros, indicados entre professores pesquisadores de universidades com reconhecida contribuição para a educação básica e formação de professores, professores em exercício nas redes estaduais, do Distrito Federal e redes municipais, bem como especialistas que tenham vínculo com as secretarias estaduais das unidades da Federação (Art. $1^{\circ}, \S$ $\left.1^{\circ}\right)$.

A portaria considera como especialistas na comissão professores e demais trabalhadores vinculados às secretarias estaduais, discurso que se altera quando o MEC diz que em 2016 "aconteceram 27 Seminários Estaduais com professores, gestores e especialistas para debater a segunda versão da BNCC" (Brasil, 2019, grifo nosso), onde os professores não encontram-se mais listados como parte do grupo de especialistas, abrindo-se precedentes para a compreensão de que um grupo de pessoas, supostamente qualificado (especialistas), reunindo ou não professores, pode elaborar um documento que prescreve, orienta e regula o que se deve ensinar nas escolas de Educação Infantil e Ensino Fundamental e, 
consequentemente, o trabalho docente. Este processo pouco claro de constituição das comissões e de prazos reduzidos de chamadas para o debate constituem um currículo como planejamento para.

\section{Planejamento para}

Analisar a atual BNCC como um planejamento para requer que a situemos no contexto das políticas neoliberais que, especialmente nos últimos anos, tem ganhado terreno fértil no meio educacional. Compartilhamos da ideia de BRANCO [et al.] (2018), ao dizer que:

À medida que o neoliberalismo se caracteriza por pregar que o estado intervenha o mínimo na economia, mantendo a regulamentação das atividades econômicas privadas num mínimo e deixe agir livremente os mecanismos de mercado, isso reflete na predominância dos mecanismos do mercado e na omissão do estado no campo social, reforçando as desigualdades já existentes. (p. 21-22).

Essa crença neoliberal encontra no sistema educacional um lugar especial para sua perpetuação, pois, uma vez que estabelece ligação direta com a reprodução do capital, vê na educação escolar a possibilidade de formar indivíduos ideais para o sistema. Os autores ainda assinalam que mesmo o campo educacional não constituindo o limite da estratégia neoliberal, ele ocupa "um lugar privilegiado, como um dos muitos elementos passíveis de serem utilizados como técnica de governo, regulação e controle social" (BRANCO [et al.], 2018, p. 22).

A política neoliberal toma as reformas educacionais necessárias e as torna seus mecanismos de perpetuação do poder. A transformações no contexto escolar são demandadas pela sociedade à medida que fazem parte da dinâmica da própria sociedade, mas devemos compreender que este não é um processo totalmente natural ou neutro, mas forjado por sujeitos que possuem interesses diversos e muitas vezes desalinhados com os interesses da coletividade, onde a educação deixa de ser uma conquista e um dever do Estado e passa a ser uma mercadoria.

Em uma de suas obras mais conhecidas, na década de 70 do século XX, Paulo Freire afirmou que "Um dos elementos básicos na mediação opressores-oprimidos é a prescrição" e que "Toda prescrição é a imposição da opção de uma consciência a outra" (FREIRE, 1983, p. 34). Logicamente ele não aplicava ali o sentido de prescrição diretamente aos documentos 
curriculares, mas às condições gerais vivenciadas pela sociedade em situação de opressão. Contudo, é neste mesmo sentido que compreendemos a organização do currículo nacional, que mais recentemente se materializou na Base Nacional Comum Curricular.

Para isso, partimos da necessidade de uma Base Nacional Comum e faz-se necessário afirmar, de início, que a BNCC é currículo. Esta é uma afirmativa que se contrapõe ao entendimento do Ministério da Educação, que, por sua vez, define a base como "um documento de caráter normativo que define o conjunto orgânico e progressivo de aprendizagens essenciais que todos os alunos devem desenvolver ao longo das etapas e modalidades da Educação Básica” (MEC, 2018)1 .

Dizer que a Base não é currículo é uma forma de falsear a autonomia das escolas e dos professores, uma vez que se de um lado confere às secretarias, bem como instituições de ensino, liberdade para formularem seus currículos, de outro lado estabelecem conhecimentos, competências e habilidades a serem desenvolvidos pelos estudantes no decorrer da educação básica, fazendo com que os currículos escolares sejam elaborados com uma finalidade principal: a de atender ao dispositivo normativo que, por seu turno, serve para regular o trabalho nas escolas, definindo as que foram mais e menos eficazes em ensinar os conteúdos comuns.

Entender a Base como um currículo oficial é, portanto, passo fundamental para que possamos vislumbrar uma BNCC democrática. Segundo Cury (2018), "A BNCC traz uma concepção de currículo travestida de direitos de aprendizagens que, sob a ótica tecnicista e meritocrática, constituem-se em deveres de aprendizagem" (p. 66). Dessa forma, ao definir o que os alunos devem aprender ao longo de sua escolarização básica, mas sem assumir a natureza curricular da base, o MEC abre precedentes para outro debate importantíssimo: o que envolve a definição de currículo.

É fato que não temos consolidada uma só definição de currículo, mas eticamente procuramos expressar através das várias definições o que o currículo espelha: as relações de trabalho (no capitalismo), as relações entre escola e sociedade, o contexto político e econômico do qual faz parte, entre outros elementos. O currículo não pode ser visto simplesmente como a organização de conteúdos selecionados por especialistas que supõem saber quais conteúdos a sociedade precisa ter acesso e como esses conteúdos são transformados através de professores e alunos em conhecimento. Antes de tudo, é forçoso

1 MINISTÉRIO DA EDUCAÇÃO. Base Nacional Comum Curricular / Disponível em: <http://basenacionalcomum.mec.gov.br/>. Acesso em: 01/08/2019. 
argumentar em defesa do caráter político da educação e do currículo, pois não fazê-lo implica posicionar-se em defesa de "uma crença positivista de neutralidade do conhecimento científico que deveria ser distribuído pela escola” (CURY, 2018, p. 70).

O planejamento para está a serviço das demandas dos grupos dominantes que expressam suas relações de poder através dos sistemas que mais precisamente regulam a convivência em sociedade. Além disso, tal manifestação de poder se faz o mais eficaz possível através da regulação do acesso aos conhecimentos e é nisto que precisamos nos ater, não pensar na extinção das prescrições, mas saber que devem contemplar, no mínimo, os sujeitos que delas se utilizam.

\section{Uma Base Nacional Comum necessária}

Este título "uma Base Nacional Comum necessária" justifica a existência das críticas em torno da BNCC, pois não nos posicionamos contra a existência de qualquer prescrição, mas de sua verticalidade e totalidade. Uma base necessária é aquela que reconhece a carência de constante de revisão, que não se quer neutra e na qual tanto importa as individualidades quanto o que indica a coletividade, ou seja, os conhecimentos comuns/universais. Neste sentido, compreendemos que

É também por meio da escola que se estabelece vínculos da cultura e conhecimentos sistematizados ao longo da história com as novas gerações. Assim, à medida que os avanços tecnológicos e as relações entre a sociedade se tornam mais complexos, a escola e o ensino público se consolidam como meios insubstituíveis e indispensáveis na formação do cidadão. (BRANCO et al., 2018, p. 13).

Por isso mesmo, se a sociedade muda constantemente, "é inevitável o repensar periódico na organização e no papel da escola e, consequentemente, nas reformas educacionais" (BRANCO [et al.], 2018, p. 13), no entanto essas reformas podem ou não estar em consonância com as realidades sociais, a depender de sua aproximação com os mecanismos de legitimação de poder, "estando mais vinculadas às crises econômicas e ao setor produtivo, priorizando, muitas vezes, o ensino para obter um profissional flexível em detrimento da formação social do cidadão" (idem).

Reforçamos esta ideia com a fala de Sacristán (2017), ao analisar o currículo prescrito:

Em todo sistema educativo, como consequência das regulações inexoráveis às quais está submetido, levando em conta sua significação social, existe 
algum tipo de prescrição ou orientação do que deve ser seu conteúdo, principalmente em relação à escolaridade obrigatória. São aspectos que atuam como referência na ordenação do sistema curricular, servem de ponto de partida para a elaboração de materiais, controle do sistema etc. A história de cada sistema e a política em cada momento dão lugar a esquemas variáveis de intervenção, que mudam de um país para outro (p. 103).

Portanto, é imperioso reconhecer tanto a natureza curricular da base e sua alocação no contexto político e social quanto a necessidade de vislumbrar que sua construção seja de fato coletiva. Nem todos os conteúdos devem constituir-se de regionalidades e tendo em conta a natureza subjetiva dos conhecimentos, pois na defesa da subjetividade, podemos também negar o conhecimento cientificamente elaborado. É neste sentido que falamos em construção coletiva, onde os conteúdos norteadores (base), aqueles acumulados por meio da cultura, não ocupem posição de centro em detrimento daqueles que constituem o saber construído cotidianamente, seja pela mediação dos saberes de referência, seja pela incorporação de novos saberes.

Ao estudar a história social do currículo, o educador inglês Ivor Goodson afirma que "o currículo escolar está longe de ser um fator neutro" e que "a nossa própria construção social encontra-se no cerne do processo através do qual procedemos à educação dos nossos filhos" (GOODSON, 1997, p. 17). Como já assinalado na primeira parte deste trabalho, faz-se necessário assumir posição frente às definições de currículo para que o vislumbremos como democrático, com a consciência de que ele é "um conhecimento ilusório e multifacetado" (idem).

O estudo de Goodson em relação às propostas de currículo nacional apresentado pelo governo britânico tem pasmosa semelhanças com os debates empreendidos no cenário brasileiro. $\mathrm{O}$ autor refuta a ideia de que o currículo nacional surja em meio a uma onda reformadora e inovadora da educação, pois "uma amnésia histórica permite que a reconstrução curricular seja apresentada como uma revolução curricular” (GOODSON, 1997, p.38), ao passo que olhares mais atentos identificam com clareza as atuantes "continuidades históricas nos objetivos e prioridades sociais e políticas”. (idem, p. 38-39).

A frágil faceta inovadora que recobre o plano de continuidades históricas serve a uma estrutura de poder que se evidencia, como já debatido, no conjunto das políticas neoliberais. É essa consciência o fundamento para se vislumbrar uma base democrática, que tenha como referência os fatores reais de sobrevivência cotidiana dos indivíduos, é o que denominamos planejamento com. Este que definimos, conforme Süssekind (2014, p. 1519), como "um conceito-verbo mas também como um monte de práticas" (grifo da autora). 


\section{Planejamento com}

Devemos nos preocupar com tudo aquilo que é definido longe do âmbito da prática. SACRISTÁN (2017, p. 102) nos chama a atenção para o fato de que

As orientações ou prescrições administrativas costumam ter escasso valor para articular a práticas dos docentes, para planejar atividades de ensino ou para dar conteúdo definido a objetivos pedagógicos, que por muito específicos que sejam e por mais concreta definição que tenham, não podem transmitir ao professor o que é preciso fazer com os alunos, o que lhes ensinar.

Vimos defendendo neste trabalho uma construção curricular coletiva e reforçamos a necessidade de se repensar a posição que ocupam os saberes de referência (conteúdos base) e aqueles construídos cotidianamente. Parece óbvia a necessidade de uma reaproximação desses saberes, o que não pode ocorrer sem que de fato sejam ouvidas as reivindicações dos professores.

Uma perspectiva de currículo apresentada por GONÇALVES (2018), em sua tese de doutorado, merece destaque, pois nela o currículo é

[...] pensado na heterogeneidade de contextos e circunstâncias das condições de existência da humanidade no mundo pós-moderno e, pensando ainda nas íntimas relações estabelecidas entre conhecimentos, ações, valores e emoções, podemos assumir que ele é expressão de múltiplas interações complexas, bem como de uma rede de representações e significados (p. 57).

É com base nesta concepção que o autor percebe e analisa dados provenientes de conversas com professoras da Rede Municipal de Três Rios-RJ, delineando possibilidades de práticas curriculares emancipatórias. As professoras expressam, dentre outras coisas, suas inquietações em relação às prescrições curriculares e suas múltiplas formas de resistência que emergem em suas práticas diárias em sala de aula. A professora representada pelo pseudônimo Débora reflete: “(...) muitas vezes, quase na maioria delas, os professores, ou sei lá quem, que pensam nas propostas de currículo e na política da educação, se esquecem o que fazemos no chão da escola" (GONÇALVES, 2018, p. 67). Outra professora (pseudônimo: Graça) complementa a fala da colega explicitando algo essencial, o caráter não neutro da educação, quando diz: “(...) o que fazemos no chão da escola é política, não no sentido de partido ou posicionamento, mas sim no sentido de orientação" (idem).

Não podemos afirmar que todas as professoras e professores de outras redes sejam tão conscientes do lugar que ocupam quanto as que falaram acima ou que nutram as mesmas 
reinvindicações, mas as falas são representativas de uma realidade cada vez mais evidente: a da mínima participação dos professores na elaboração das prescrições, que, em suma, tratam a noção de currículo "de modo despido de complexidade, como sendo um objeto, um documento, para assumir o papel de arma com um poder de educaçãodestruição em massa" (SÜSSEKIND, 2014, p. 1514, grifos da autora).

Pensar um planejamento com requisita uma mudança de perspectiva em relação ao currículo, pois, como já dito, ele é também "um monte de práticas" e, assim sendo, não há como compreendê-lo apenas no âmbito da prescrição, mas envolto em todas as disputas, projetos de poder e manifestações de resistência. Professores, alunos, pais e gestão escolar fazem o currículo cotidianamente, as diferentes formas de compreensão dos conteúdos escolares são resultantes de uma vivencia coletiva que se manifesta no indivíduo, formando o seu jeito de ser e de ser visto.

O currículo não contém todo o conteúdo possível, assim como não é somente complemento desprovido de intencionalidade. Cada currículo revela também o seu tempo, suas aberturas e amarras, portanto, assim como é possível manter estruturas de poder através do currículo, é possível também desfazê-las exercendo-se a democracia. É por meio do planejamento com que as invisibilidades são repensadas, onde a homogeneidade dá lugar a pluralidade, onde o ato de ensinar é intrínseco ao de aprender.

\section{Conclusão}

Os principais debates em relação a Base Nacional Comum Curricular têm como núcleo a relação impositiva do currículo, no âmbito das políticas neoliberais. Não se trata ainda de uma construção coletiva, mas de uma padronização e homogeneização dos conteúdos e das aulas, onde os professores são meros executores de atividades prescritas e precisam lidar com o encargo de manter a aprendizagem dos alunos em função das demandas do capitalismo.

As diferentes formas de definir currículo são essenciais, uma vez que contemplam, além de documentos normativos, uma "confluência de práticas" cotidianas nas salas de aulas, daí a relevância das diversas perspectivas teóricas que complementam o debate e situam a base como um dos modelos curriculares, diferentemente do que quer a oficialidade. Antes de serem pensadas como inovadoras, as políticas de reformas curriculares também precisam ser problematizadas no âmbito das realidades escolares e revistas em suas potencialidades. 
Não descartamos a possibilidade de que especialistas possam ter ideias favoráveis à educação, de que possam contribuir com a sua melhoria, mas vemos como no mínimo preocupante que a eles caiba o papel de elaborar e aos professores o de executar o currículo e, mais ainda, que os resultados da execução não sejam revistos, que as reivindicações do professores não sirvam para a constante proposição de reformas, ficando estas sob o encargo das grandes empresas que reforçam o modelo do capital e, em consequência, as desigualdades econômicas e sociais.

Reconhecendo o espaço em que está situado o currículo, um espaço de poder e de disputas, em contrapartida, vislumbramos um currículo humanizante, pensado a partir da pluralidade de sujeitos, que tenha como referência a possibilidade de alcançar a todos democraticamente, ou seja, superar as diferenças pelo próprio reconhecimento delas e não por sua ocultação.

\section{REFERENCIAS}

BRANCO, E. P. [et al.]. A implementação da base nacional comum curricular no contexto das políticas neoliberais / Curitiba: Appris, 2018.

BRASIL. Documento final da $2^{\text {a }}$ Conferência Nacional pela Educação (Conae). Fórum Nacional de Educação (FNE), 2014. Disponível em: <http://fne.mec.gov.br/images/doc/DocumentoFina240415.pdf> Acesso em: 02/08/2019.

BRASIL. Constituição da República Federativa do Brasil de 1988. Presidência da República / Brasília, 5 de outubro de 1988. Disponível em: <http://www.planalto.gov.br/ccivil_03/constituicao/constituicao.htm> Acesso em: 02/08/2019.

BRASIL. Site do Ministério da Educação. Base Nacional Comum Curricular / 2019. Disponível em: <http://basenacionalcomum.mec.gov.br/>. Acesso em: 01/08/2019.

BRASIL. Lei de Diretrizes e Bases da Educação Nacional - LDBEN / LEI No 9.394 de 20 de dezembro de 1996. Disponível em: 〈http://portal.mec.gov.br/secad/arquivos/pdf/ldb.pdf> Acesso em: 02/08/2019.

BRASIL. Portaria n 592, de 17 de junho de 2015. Ministério da Educação / Diário Oficial da União, 18 de junho de 2015, Seção 1, Página 16. Disponível em: <https://www.jusbrasil.com.br/diarios/94124972/dou-secao-1-18-06-2015-pg-16> Acesso em: 04/08/2019. 
CURY, C. R. J. Base Nacional Comum Curricular: dilemas e perspectivas / Carlos Roberto Jamil Cury, Magali Reis, Teodoro Adriano Costa Zanardi. - São Paulo: Cortez, 2018.

GONÇALVES, R. M. Bricolagens praticadas e politicaspráticas de currículos nos cotidianos escolares / Tese (Doutorado) - Universidade do estado do Rio de Janeiro. Faculdade de Educação, 2018.

GOODSON, I. F. A construção social do currículo / Trad. Maria João Carvalho - Educa, Universidade de Lisboa, Lisboa, 1997.

SACRISTÁN, J. G. O currículo: uma reflexão sobre a prática / Trad. Ernani F. da Fonseca Rosa ; Revisão técnica: Maria da Graça Souza Horn. - 3. Ed. - Porto Alegre : Penso, 2017. $352 \mathrm{p}$.

SÜSSEKIND, M. L. As (im)possibilidades de uma base comum nacional / Revista eCurrículum, São Paulo, v.12, n.03, p. 1512 - 1529 / out,/dez.2014.

\section{SOBRE OS AUTORES:}

\section{Rafael Marques Gonçalves}

Doutor em Educação, UERJ/ProPed; Universidade Federal do Acre-Brasil; Programa de PósGraduação e Educação; Grupo de Pesquisas em Políticas, Práticas e Currículos. E-mail: rafamg02@gmail.com

(iD http://orcid.org/0000-0002-9038-1542

\section{Tânia Mara Rezende Machado}

Doutora em Educação, PUC/SP; Universidade Federal do Acre-Brasil; Programa de PósGraduação e Educação; Grupo de Estudos e Pesquisas em Trabalho Docente e Desenvolvimento Profissional. E-mail: taniaufac@gmail.com

(iD http://orcid.org/0000-0001-5721-9079

\section{Maria José Nascimento Correia}

Mestranda em Educação, UFAC; Universidade Federal do Acre-Brasil; Programa de PósGraduação e Educação; Grupo de Estudos e Pesquisas em Trabalho Docente e Desenvolvimento Profissional. E-mail: mcorreiaac@gmail.com

(iD http://orcid.org/0000-0003-4064-7100 